\title{
Interpretation and adherence to the updated risk-stratified guideline for colonoscopy surveillance after polypectomy - a nationwide survey
}

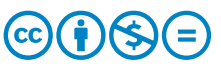

\author{
Authors \\ surveillance \\ Institutions \\ 1 Department of Public Health, Erasmus Medical Centre, \\ Rotterdam, The Netherlands \\ 2 Department of Gastroenterology, The Netherlands \\ Cancer Institute, Antoni van Leeuwenhoek Hospital, \\ Amsterdam, The Netherlands \\ 3 Department of Gastroenterology and Hepatology, \\ Academic Medical Center, Amsterdam, The Netherlands
}

Miriam P. van der Meulen ${ }^{1}$, Ida J. Korfage ${ }^{1}$, Else-Mariëtte B. van Heijningen ${ }^{1}$, Harry J. de Koning ${ }^{1}$, Monique E. van Leerdam $^{2}$, Evelien Dekker ${ }^{3}$, Iris Lansdorp-Vogelaar ${ }^{1}$, on behalf of the working group on the guideline for colonoscopy

submitted 14.7.2019

accepted after revision 24.4.2020

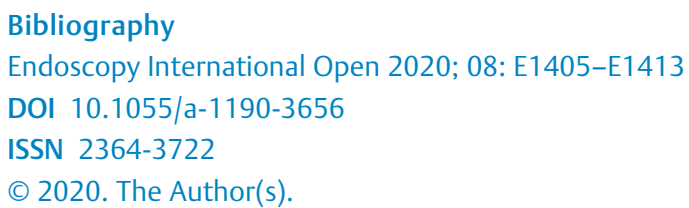

This is an open access article published by Thieme under the terms of the Creative Commons Attribution-NonDerivative-NonCommercial License, permitting copying and reproduction so long as the original work is given appropriate credit. Contents may not be used for commecial purposes, or adapted, remixed, transformed or built upon. (https://creativecommons.org/licenses/by-nc-nd/4.0/)

\section{Corresponding author}

Miriam P. van der Meulen, Department of Public Health, Erasmus MC, University Medical Center Rotterdam, PO Box 2040, 3000 CA Rotterdam, The Netherlands Fax: +31-10-7038474

m.vandermeulen.1@erasmusmc.nl

Supplementary material is available under https://doi.org/10.1055/a-1190-3656

\section{ABSTRACT}

Background and study aims Low adherence to the Dutch guideline for colonoscopy surveillance after polypectomy led to release of a new guideline in 2013. This new guideline was risk-stratified at a more detailed level than the previous one to achieve more efficient use of colonoscopy resources. This study assessed the feasibility of the risk-stratified guideline by evaluating correct interpretation of and adherence to this guideline.

Methods Based on semi-structured interviews with 10 gastroenterologists, we developed an online survey to evaluate gastroenterologists' recommendations for surveillance in 15 example cases of patients with polyps. If recommended intervals differed from the new guideline, respondents were asked to indicate their motives for doing so.

Results Ninety-one of 592 (15.4\%) invited gastroenterologists responded to at least one case, of whom 84 (14.2\%) completed the survey. Gastroenterologists gave a correct recommendation in a median of 10 of 15 cases and adherence per case ranged from $14 \%$ to $95 \%$ (median case $76 \%$ ). The two cases that addressed management of serrated polyps were least often answered correctly (14\% and $28 \%$ correct answers). Discrepancies were mainly due to misinterpretation of the guideline with respect to serrated polyps (48\%) or misreading of the questions (30\%).

Conclusions Median adherence to the updated colonoscopy surveillance guideline of $76 \%$ seems reasonable, and is higher than adherence to the previous guideline (range: 22\%-80\%, median 59\%). This shows that detailed (more complex) risk stratification for designation of a surveillance interval is feasible. Adherence could potentially be improved by clarifying correct interpretation of serrated polyps.

\section{Introduction}

Colorectal cancer (CRC) is the second most common cause of cancer mortality in the western world [1]. Individuals with adenomas are at increased risk of developing metachronous ade- nomas and CRC, even after the adenomas have been completely removed [2-4]. Therefore, colonoscopy surveillance after polypectomy is recommended [5,6]. Frequency of colonoscopy surveillance and adherence to surveillance recommendations are important, because too little surveillance is associated 
with risk of diminishing the preventive effect of the surveillance program for CRC, while too intensive surveillance exposes patients to unnecessary risks and burden and waste of colonoscopy as well as financial resources.

Colonoscopy is a scarce resource and many countries face waiting lists for these procedures [7,8]. With implementation and expansion of CRC screening programs throughout the world [9], demand for colonoscopies will further increase.

Before introduction of mass screening, colonoscopies for surveillance after polypectomy encompassed about $13 \%$ of all colonoscopies conducted in the Netherlands [10]. The recently begun CRC screening program will result in an increase in adenoma diagnoses, eventually resulting in an increasing number of patients that meet the criteria for surveillance colonoscopy. This underscores the importance of efficient use of colonoscopy capacity, and thus, also of efficient surveillance strategies.

Colonoscopy capacity, however, is often not used efficiently for surveillance. Current international guidelines only consider presence or absence of risk factors for metachronous advanced neoplasia, but do not take into account combinations of risk factors. Several surveys showed suboptimal adherence to guidelines for surveillance after polypectomy in daily practice, with clinicians often recommending too short surveillance intervals [11-13]. A Dutch study reported on six example cases that were assigned correct recommendations ranging from $22 \%$ to $80 \%$ (median $59 \%$ ). In most of the incorrect recommendations, gastroenterologists used shorter surveillance intervals than prescribed by the national guideline [12]. This was caused by clinicians often incorporating other adenoma characteristics, like adenoma histology and size, into their recommendation, even though at that time the Dutch surveillance guidelines only differentiated the recommended surveillance interval by adenoma multiplicity [12].

The updated risk-stratified guideline for colonoscopy surveillance introduced in 2013 incorporated multiplicity, size, location, and histology of adenomas as well as presence of large serrated lesions [14]. Through a score chart, these polyp characteristics are combined into a risk score $(0-5)$ to optimize risk stratification of patients for designation of a surveillance interval. However, this new guideline is more complex than the previous guideline and most international guidelines. That may cause gastroenterologists to misunderstand or misinterpret the guideline, or potentially even not use it all, eventually resulting in low adherence to the recommendations. Therefore, the aim of our study was to evaluate gastroenterologists' interpretation and adherence to this new guideline.

\section{Materials and methods}

\section{Design}

To assess correct interpretation of and adherence to the Dutch guideline for colonoscopy surveillance after polypectomy, we developed an online survey consisting of 15 example cases of patients that underwent colonoscopy with polypectomy. The survey was pilot-tested during semi-structured interviews with 10 gastroenterologists. We sent the survey to all gastroenterologists in the Netherlands and asked them to designate their surveillance recommendation for each case. If recommendation(s) differed from the new guideline, we asked for their motives for doing so for a maximum of two random example cases. The survey was estimated to take approximately 15 minutes to complete and that information was provided to the gastroenterologists.

\section{Dutch guideline for colonoscopy surveillance after polypectomy}

The new Dutch guideline for surveillance after polypectomy was introduced in 2013 [14]. The surveillance interval is based on the number of adenomas and presence of at least one large adenoma ( $\geq 10 \mathrm{~mm}$ ), at least one villous adenoma (>75\% villous component) and/or at least one proximal adenoma. Serrated polyps (including hyperplastic polyps, sessile serrated adenomas/polyps and traditional serrated adenoma) are incorporated in the guideline only if at least one serrated polyp measures $\geq 10 \mathrm{~mm}$. Other characteristics (total number, localization) of serrated polyps are not taken into account. High-grade dysplasia (HGD) in adenomas is not incorporated as a risk factor in the guideline as it is not confirmed to be an independent risk factor, probably because HGD is significantly associated with other factors such as size. Using a score chart, the polyp characteristics are combined into a risk score (0-5) ( Table 1$)$. The total risk score indicates a recommended surveillance interval of 3 or 5 years, or no surveillance at all.

\section{Survey}

The survey consisted of three parts. The first part (baseline questions) contained seven questions on (demographic) characteristics of the gastroenterologist: gender; age; type of hospital; specialization; number of colonoscopy procedures per year; years of experience, and if they perform colonoscopies for the national screening program.

The second part consisted of 15 example cases of patients that underwent colonoscopy with polypectomy. To avoid bias and disadvantages for the later example cases if respondents could not finish the complete survey, there were two versions of the survey that only differed regarding the order of the example cases. The example cases varied in age, gender, adenoma/polyp number, size and location of adenomas, grade of dysplasia and presence of (tubulo)villous histology ( $\triangleright$ Table 2, Appendix 2). Respondents were informed that unless noted otherwise, all patients were in good health; had no familial risk for colorectal cancer; had undergone their first colonoscopy; bowel preparation was good; the cecum was reached; and the polyp was removed in one piece and endoscopically complete.

In each case, the gastroenterologist was asked to recommend the surveillance interval. Response options were: interval of $<1$ to 10 years; no surveillance; surveillance only if the patient was in good condition (at a 3- or 5-year interval); and referral to the clinical geneticist (Appendix 2).

In the third part of the survey, respondents were given feedback on the recommendations they had given in Part 2. For each case in which the recommendation did not meet the guideline, the respondent was shown a table with the interval they recommended versus the guideline recommendation. 
- Table 1 Score chart for the Dutch guideline for colonoscopy surveillance after polypectomy [14]

Table 1a: Score table for presence of adenoma characteristics and serrated polyps ${ }^{1}$

\begin{tabular}{|l|l|l|}
\hline Polyp Characteristics & Values & Points \\
\hline - Number of adenomas & 1 & 0 \\
\hline & $2-4$ & 1 \\
\cline { 2 - 3 } & $\geq 5$ & 2 \\
\hline $\begin{array}{l}\text { - Presence of at least one adeno- } \\
\text { ma } \geq 10 \text { mm and/or one large } \\
\text { serrated polyp } \geq 10 \text { mm }^{2}\end{array}$ & No & 0 \\
\hline $\begin{array}{l}\text { Presence of at least one villous } \\
\text { adenoma }\end{array}$ & No & 1 \\
\hline $\begin{array}{l}\text { - Presence of at least one proximal } \\
\text { adenoma }\end{array}$ & Yes & 0 \\
\hline & No & 0 \\
\hline
\end{tabular}

Total risk score

Table 1b: Surveillance interval based on the adenoma risk score

\begin{tabular}{|l|l|}
\hline Score during index colonoscopy & $\begin{array}{l}\text { Interval after index colonos- } \\
\text { copy }\end{array}$ \\
\hline - 0 & No surveillance $^{5}$ \\
\hline - $1-2$ & 5 years \\
\hline - $3-5$ & 3 years \\
\hline $\begin{array}{l}\text { Score during subsequent colonos- } \\
\text { copy }\end{array}$ & $\begin{array}{l}\text { Interval after subsequent } \\
\text { colonoscopy }\end{array}$ \\
\hline - 0 & 5 years \\
\hline - $1-2$ & 5 years \\
\hline - $3-5$ & 3 years \\
\hline
\end{tabular}

Stopping age of surveillance: 75 years, unless the wish and condition of the patient justify a different stopping age

${ }^{1}$ A patient with 5 proximal serrated polyps of which $2 \geq 10 \mathrm{~mm}$ fulfil the WHO criteria of the serrated polyposis syndrom; see the guideline of hereditary colorectal cancer.

${ }^{2}$ A serrated polyp encompasses: hyperplastic polyps, sessile serrated polyps/adenomas and traditional serrated adenomas

${ }^{3}$ An adenoma with at least $75 \%$ villous histology.

${ }^{4}$ Proximal is defined as cecum, colon ascendens, colon transversum and flexura lienalis

${ }^{5}$ Patients with a score of 0 during index colonoscopy are advised to not undergo surveillance colonoscopy. These patient are sent back to the national screening programme in 10 years if aged $55-75$ years at that moment.

${ }^{6}$ For patients in which a high-risk adenoma (score $\geq 3$ ) was never detected, surveillance can be ended after two subsequent negative colonoscopies. These patient are sent back to the national screening programme in 10 years if aged $55-75$ years at that moment.

Subsequently, respondents were asked about their motives for deviation for a maximum of two random example cases. Response options were: believing that the answer was in agreement with the guideline; not having read the question correctly; unfamiliarity with the new guideline; based on scientific evidence or clinical experience; or an answer in the free text field (Appendix 2).

\section{Pilot-tests}

\section{Interviews}

Ten gastroenterologists were interviewed between May and July 2014 (Appendix 1). The selected gastroenterologists differed in age, gender, setting (regional or academic hospital), and region. One of the authors (MvdM) conducted all interviews, which were audiotaped. The interviews were semi-structured, starting with open questions on what gastroenterologists considered advantages and bottlenecks of the guideline. Then, they were presented with five cases and asked what interval they would recommend and why. Based on the response of the interviewed gastroenterologists, the cases were improved and several answers for why people would potentially deviate from the current guideline were added.

\section{Online pilot}

After enhancement of the survey based on the interview findings, the survey was validated by five medical researchers in gastroenterology from the Academic Medical Center (AMC) and the Netherlands Cancer Institute.

\section{Survey distribution}

The online survey was sent by email to all 594 registered gastroenterologists in the Dutch Gastroenterology Association in December 2014. A reminder about the survey was sent 6 weeks later, in January 2015. The survey was anonymous and written in Dutch.

\section{Statistical analyses}

Statistical analyses were conducted with SPSS version 22.0 (IBM corporation, United States). To be considered as a respondent, at least four baseline questions had to be answered. Descriptive statistics were used to analyze the data; medians and interquartile range (IQR) were calculated for non-normally distributed data. Outcomes were the number of respondents, median number of correct recommendations per respondent - for those who responded to all cases -, and the number of correct recommendations per case. Differences between subgroups in correct recommendations per respondent were tested with the Mann-Whitney U test.

\section{Results}

Of 592 invitees, 91 (15.4\%) responded to at least one case. One respondent was excluded as he or she did not actively perform colonoscopies. Of the 91 responders, 84 gastroenterologists ( $14.2 \%$ of 592 invitees) responded to all cases.

Sixty-five percent of the respondents were male and the median age was 43 years old ( $\triangleright$ Table 3 ). Most respondents worked in a hospital without gastroenterology trainees (43\%), most had 0 to 10 years of experience $(51 \%)$, performed more than 300 colonoscopies per year ( $70 \%)$, and performed colonoscopies for the national bowel cancer screening program (63\%). Thirty-six percent of respondents indicated that they did not consult the guideline during the questionnaire, while $48 \%$ used the pocket card for the guideline and $10 \%$ used the app. 
Table2 Short description of the 15 example cases with recommended interval and results per example case.

Case description

Common cases

\section{Results per case}

\begin{tabular}{|c|c|c|c|c|c|c|c|c|c|c|c|c|c|c|}
\hline & Age & G & \# $A D^{1}$ & $\begin{array}{l}\text { Size } \\
(\mathrm{mm})\end{array}$ & Vill. & HGD & $\begin{array}{l}\# \\
\text { prox }^{1}\end{array}$ & $\begin{array}{l}\text { Recommen- } \\
\text { ded interval }\end{array}$ & N & $\%$ corr & \% early & \% late & $\begin{array}{l}\% \text { no } \\
\text { surv }\end{array}$ & \% other \\
\hline 1 & 60 & $M$ & 1 & 8 & $\mathrm{~T}$ & no & 0 & $\begin{array}{l}\text { No surveil- } \\
\text { lance }\end{array}$ & 86 & $84 \%$ & $16 \%$ & $0 \%$ & na & $0 \%$ \\
\hline 2 & 69 & $M$ & 1 & 12 & $T$ & no & 0 & $5 y$ & 89 & $91 \%$ & $1 \%$ & $1 \%$ & $3 \%$ & $3 \%$ \\
\hline 3 & 54 & $M$ & 1 & $20^{2}$ & TV & no & 1 & $5 y$ & 85 & $52 \%$ & $47 \%$ & $1 \%$ & $0 \%$ & $0 \%$ \\
\hline 4 & 62 & $\mathrm{~F}$ & 2 & $22^{2}$ & V & no & 0 & $3 y$ & 84 & $79 \%$ & $6 \%$ & $15 \%$ & $0 \%$ & $0 \%$ \\
\hline 5 & 63 & $\mathrm{~F}$ & 4 & 9 & V & no & 2 & $3 y$ & 84 & $90 \%$ & $0 \%$ & $7 \%$ & $0 \%$ & $2 \%$ \\
\hline 6 & 60 & $\mathrm{~F}$ & 5 & 12 & $\mathrm{~T}$ & no & 4 & $3 y$ & 84 & $95 \%$ & $2 \%$ & $1 \%$ & $0 \%$ & $1 \%$ \\
\hline 7 & 79 & $M$ & 5 & 8 & $\mathrm{~T}$ & no & 3 & $\begin{array}{l}\text { Only if heal- } \\
\text { thy, then } 3 y^{3}\end{array}$ & 84 & $52 \%$ & $1 \%$ & $8 \%$ & $11 \%$ & $27 \%$ \\
\hline 8 & 75 & $M$ & 4 & 12 & $T$ & yes & 0 & $\begin{array}{l}\text { Only if heal- } \\
\text { thy, then } 5 y^{3}\end{array}$ & 84 & $31 \%$ & $40 \%$ & $0 \%$ & $4 \%$ & $25 \%$ \\
\hline 9 & 65 & $M$ & 1 & 11 & TV & yes & 0 & $5 y$ & 88 & $76 \%$ & $17 \%^{4}$ & $1 \%$ & $2 \%$ & $3 \%$ \\
\hline
\end{tabular}

Serrated adenomas/polyps

\begin{tabular}{|c|c|c|c|c|c|c|c|c|c|c|c|c|c|}
\hline & Age & G & $\# \mathbf{S P}{ }^{1}$ & $\begin{array}{l}\text { Size } \\
(\mathrm{mm})\end{array}$ & & $\begin{array}{l}\# \\
\text { prox }^{1}\end{array}$ & & $\mathbf{N}$ & $\%$ corr & \% early & \% late & $\begin{array}{l}\text { \%no } \\
\text { surv }\end{array}$ & \% other \\
\hline 10 & 58 & $\mathrm{~F}$ & 1 & 8 & & 1 & $\begin{array}{l}\text { No surveil- } \\
\text { lance }\end{array}$ & 85 & $14 \%$ & $86 \%$ & $0 \%$ & na & $0 \%$ \\
\hline \multirow[t]{3}{*}{11} & 54 & $\mathrm{~F}$ & 2 & 12 & & 2 & $5 y$ & 86 & $28 \%$ & $72 \%$ & $0 \%$ & $0 \%$ & $0 \%$ \\
\hline & \multicolumn{13}{|c|}{ Family history } \\
\hline & Age & G & Score & FM & $\begin{array}{l}\text { Age } \\
\text { FM }\end{array}$ & $\begin{array}{l}\text { Previous exami- } \\
\text { nation }\end{array}$ & & $\mathbf{N}$ & $\%$ corr & \% early & \% late & $\begin{array}{l}\% \text { no } \\
\text { surv }\end{array}$ & $\%$ other \\
\hline 12 & 51 & M & 2 & Brother & $<50$ & $\begin{array}{l}\text { Yes, no heredi- } \\
\text { tary CRC }\end{array}$ & $5 y$ & 84 & $83 \%$ & $14 \%$ & $0 \%$ & $0 \%$ & $2 \%$ \\
\hline 13 & 53 & M & 1 & Sister & $<50$ & no & $\begin{array}{l}\text { Refer to ge- } \\
\text { neticist }\end{array}$ & 88 & $58 \%$ & $0 \%$ & $0 \%$ & $0 \%$ & $42 \%$ \\
\hline
\end{tabular}

\section{Negative colonoscopies}

\begin{tabular}{|c|c|c|c|c|c|c|c|c|c|c|c|}
\hline & Age & G & $\begin{array}{l}\text { Initial } \\
\text { Score }\end{array}$ & \# neg. colo ${ }^{1}$ & & N & $\%$ corr & \% early & \% late & $\begin{array}{l}\% \text { no } \\
\text { surv }\end{array}$ & $\%$ other \\
\hline 14 & 69 & M & $4^{5}$ & 1 & $5 y$ & 86 & $88 \%$ & $5 \%$ & $2 \%$ & $3 \%$ & $1 \%$ \\
\hline 15 & 63 & $\mathrm{~F}$ & $2^{5}$ & 2 & $\begin{array}{l}\text { No surveil- } \\
\text { lance }\end{array}$ & 86 & $73 \%$ & $23 \%$ & $0 \%$ & na & $3 \%$ \\
\hline \multicolumn{6}{|c|}{ TOTAL } & 1283 & $66 \%$ & $22 \%$ & $3 \%$ & $2 \%$ & $7 \%$ \\
\hline
\end{tabular}

G, gender; \# AD, the number of adenomas; Size, size of the largest lesion Vill, presence of villousness; T, tubular adenoma; TV, tubulovillous adenoma; $V$, villous adenoma; HGD, presence of high-grade dysplasia

${ }^{1}$ prox, the number of proximal adenomas; \#SP, number of serrated polyps; FM, family member with CRC diagnoses. \# neg. colo=number of previous negative colonoscopies; \% corr $=\%$ of answers correct, according to the guideline (underlined $\leq 50 \%$ correct, italic $\leq 70 \%$ correct) $\%$ early $=\%$ of answers with a shorter interval than recommended; \% late $=\%$ of answers with a longer interval than recommended; $\%$ no surv $=\%$ of answers with no surveillance while this is not recommended; $\%$ other $=\%$ of answers with another answer (underlined $\geq 40 \%$ of respondents, italic $\geq 15 \%$ of respondents)

${ }^{2}$ In the cases with adenomas $\geq 20 \mathrm{~mm}$ we describe that patients had had another colonoscopy after 6 months at which no residual tissue was found.

${ }^{3}$ If an individual will be 75 at the subsequent screening, then surveillance should only take place if the individual is still healthy, and an interval is based on the adenoma risk score. We defined all answers containing a shorter interval then recommend based on the adenoma risk score as "early", we defined all answers containing a longer interval then recommend based on the adenoma risk score as "late" and an answer with the same interval but without the addition that the patient should only be screened if healthy as "other".

${ }^{4} 10$ of 15 of the respondents with an answer with a too short interval, answered they would offer a surveillance colonoscopy within a year.

${ }^{5}$ Full findings at the initial colonoscopy were: 69-year-old male: two adenomas: Polyp A was a distal villous adenoma of $12 \mathrm{~mm}$. Polyp B was a proximal tubular adenoma of $8 \mathrm{~mm}$ with low-grade dysplasia; 63-year-old female: two adenomas: Polyp A was a distal tubular adenoma of $5 \mathrm{~mm}$ with low-grade dysplasia. Polyp B was a distal tubular adenoma of $12 \mathrm{~mm}$ with low-grade dysplasia. 
- Table 3 Baseline characteristics of respondents $(N=91)$.

\begin{tabular}{|c|c|c|}
\hline Variable & \multicolumn{2}{|c|}{$N=99$} \\
\hline Age & \multicolumn{2}{|c|}{ (median) 43 (IQR 35-52) } \\
\hline \multicolumn{3}{|l|}{ Gender } \\
\hline - Males & 64 & $65 \%$ \\
\hline - Females & 35 & $35 \%$ \\
\hline \multicolumn{3}{|l|}{ Type of hospital } \\
\hline - Academic & 19 & $19 \%$ \\
\hline - Non-academical teaching hospital & 37 & $38 \%$ \\
\hline - Peripheral hospital & 42 & $43 \%$ \\
\hline - Missing & 1 & \\
\hline \multicolumn{3}{|l|}{ Specialization } \\
\hline - Gastroenterologist & 92 & $95 \%$ \\
\hline - Fellow & 5 & $5 \%$ \\
\hline - Missing & 2 & \\
\hline \multicolumn{3}{|l|}{ Years of experience with colonoscopies } \\
\hline - No experience & 2 & $2 \%$ \\
\hline - 0 to 10 & 50 & $51 \%$ \\
\hline . 10 to 20 & 21 & $21 \%$ \\
\hline . 20 to 30 & 18 & $18 \%$ \\
\hline - 30 to 40 & 6 & $6 \%$ \\
\hline . $>40$ & 2 & $2 \%$ \\
\hline \multicolumn{3}{|l|}{ Colonoscopies per year } \\
\hline . $<150$ & 10 & $10 \%$ \\
\hline . $150-300$ & 19 & $20 \%$ \\
\hline - $>300$ & 68 & $70 \%$ \\
\hline . Missing & 2 & \\
\hline \multicolumn{3}{|c|}{ Performing colonoscopies for the screening program } \\
\hline - Yes & 61 & $63 \%$ \\
\hline . No & 36 & $37 \%$ \\
\hline - Missing & 2 & \\
\hline \multicolumn{3}{|l|}{ Use of source during questionnaire } \\
\hline - None & 29 & $36 \%$ \\
\hline - App & 8 & $10 \%$ \\
\hline - Pocket card & 39 & $48 \%$ \\
\hline - Website & 2 & $2 \%$ \\
\hline - 2 sources & 3 & $4 \%$ \\
\hline . Missing & 18 & \\
\hline
\end{tabular}

Eighty-four respondents indicated correct recommendations for all cases in a median of 10 (out of 15) cases (IQR 811 ) ( $\triangleright$ Table 4 and $\triangleright$ Fig. 1 ). The number of correct recommen- dations did not differ by gender, age, type of hospital, or participation in the screening program, but consulting the guideline during the questionnaire was associated with an increase in adherence $(P=0.015)$.

The cases received a correct recommendation ranging from $14 \%$ to $95 \%$ per case (median case $76 \%$ ) (> Table 2 ). For all cases combined, a mean of $66 \%$ of recommendations were correct, $22 \%$ of the recommended intervals were shorter than the guideline, $3 \%$ of the given recommended intervals were longer than the guideline, $7 \%$ gave no surveillance interval, but an alternative recommendation while a surveillance interval was recommended (such as referral to a clinical geneticist, or only referral if the patients was in good condition) and $2 \%$ recommended no surveillance at all while the guideline did recommend surveillance. In $48 \%$ of the discrepant cases, gastroenterologists were convinced they had recommended the correct interval, while in $30 \%$ of the discrepant cases, gastroenterologists had not read the question correctly ( $\triangleright$ Table 5 ).

The recommendation for surveillance was least often correct for the cases on serrated lesions (case 10, 14\% correct, and case $11,28 \%$ correct) (\Table 2 ). All discrepant answers recommended a shorter interval ( $86 \%$ and $72 \%$ ) of which $92 \%$ and $95 \%$ recommended the interval that would be correct if serrated polyps were scored the same as conventional adenomas. In $78 \%$ and $65 \%$, respectively, of these discrepant cases, gastroenterologists had the impression they had recommended the correct interval. Thirteen percent and $26 \%$, respectively, answered that they had not read the question correctly ( $\triangleright \mathrm{Ta}$ ble 5).

Next, cases with an older patient ( $\geq 75$ years) were least often answered correctly, at $31 \%$ for Case 8 and $52 \%$ for Case 7 ( Table 2). In the case of a 75-year-old male with four adenomas and one adenoma with HGD (Case 8 ), $40 \%$ of respondents recommended a shorter interval than the guideline and $25 \%$ of respondents recommended surveillance after 5 years. Responders explained their discrepancy with the guideline for these cases because they were either convinced their answer was in accordance with the guideline or they had not read the question correctly ( $\downarrow$ Table 5 ). Of those who provided an answer for Cases 7 and 8 in the free text field, 12 of 14 mentioned they did not consider age or the condition of the older patient in their answer. In the case of a 79-year-old male with five adenomas (Case 7), the correct answer would be to recommend no surveillance, unless the patient remains in good condition, then in 3 years. Eleven percent of respondents would not recommend any surveillance regardless of physical condition, and $26 \%$ of respondents recommended surveillance after 3 years. If you assume that after these 3 years, everyone would examine these older patients if they are still in good condition, $78 \%$ of cases would be answered correctly.

The case with a large tubulovillous adenoma (Case 3) was correctly answered by only half (52\%) of the gastroenterologists. If incorrect, recommended intervals were almost always too short ( $\triangleright$ Table 2 ). Discrepancies were again mainly due to misinterpretation of the guideline (62\%). Three of four answers in the free text field explained that they scored the tubulovillous adenoma equal to villous adenoma. 


\begin{tabular}{|c|c|c|c|c|}
\hline & & $\mathbf{N}$ & Score out of 15 cases & $P$ value \\
\hline \multirow[t]{2}{*}{ Gender } & Men & 51 & 10 & \\
\hline & Women & 33 & 10 & 0.81 \\
\hline \multirow[t]{2}{*}{ Age } & $<40$ & 37 & 11 & \\
\hline & $>40$ & 47 & 10 & 0.62 \\
\hline \multirow[t]{2}{*}{ Academic hospital } & Yes & 16 & 11 & \\
\hline & No & 67 & 10 & 0.44 \\
\hline \multirow[t]{2}{*}{ Performing colonoscopies for the CRC screening program ${ }^{1}$} & Yes & 51 & 11 & \\
\hline & No & 31 & 10 & 0.71 \\
\hline \multirow{2}{*}{ Use of source ${ }^{1}$} & Yes & 29 & 11 & \\
\hline & No & 52 & 9 & 0.02 \\
\hline Total & & & 10 & \\
\hline
\end{tabular}

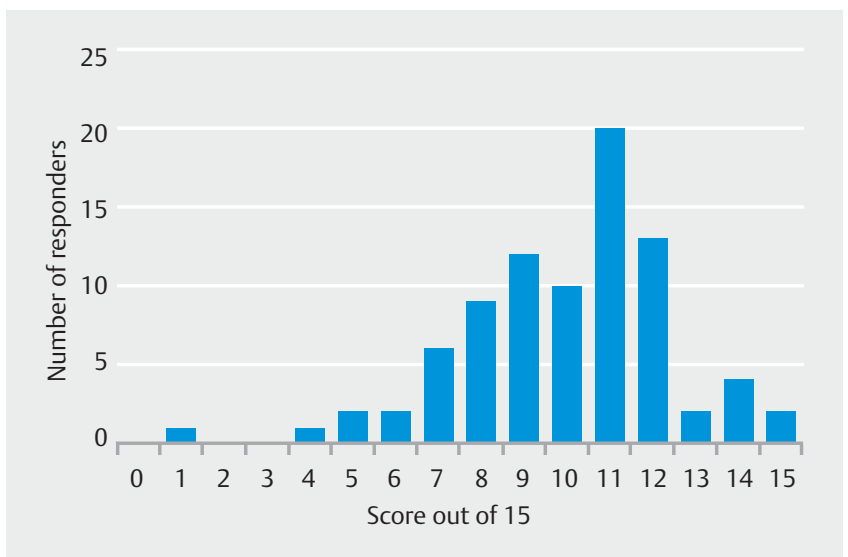

-Fig. 1 Distribution of scores for 15 example cases (number of correct answers according to the guideline) from respondents who answered all example cases $(n=84)$.

Remarkable about the case of the 65-year-old male with one adenoma with HGD (Case 9) was that even though $76 \%$ of the respondents answered correctly, the incorrect answers had a large discrepancy with the interval recommended by the guideline. Eleven percent of the respondents recommended surveillance colonoscopy within 1 year, whereas a 5-year interval is recommended by the guideline. Two of six gastroenterologists that explained their discrepancy from the guideline for this case responded that they consider lesions with HGD as high risk.

A new aspect in the guideline is that no surveillance is indicated if patients have only one distal non-advanced adenoma (Case 1 ). This was correctly recommended by $84 \%$ of respondents.

The remaining eight cases were correctly answered by a median of $86 \%$ ( $58 \%$ to $95 \%$ per case) of the respondents.

\section{Discussion}

Using a survey with 15 example cases, we showed that the cases were assigned a recommend surveillance interval in agreement with the current guideline in $14 \%$ to $95 \%$ per case (median case $76 \%$ ) and the gastroenterologists gave a correct recommendation in a median of 10 cases. Cases involving serrated polyps or elderly patients were most often answered incorrectly.

As large interobserver and intraobserver variation exists among pathologists for diagnosis of various types of serrated polyps, serrated polyps are treated as one histological entity in the guideline. To prevent patients with only small hyperplastic polyps from receiving a surveillance recommendation, number and location of serrated polyps does not impact length of surveillance interval in the guideline [14]. In our survey, almost all discrepant recommendations would have been correct if serrated polyps were scored the same way as conventional adenomas. We therefore recommend providing further clarification in the guideline on how to deal with serrated polyps. This could potentially be accompanied by further teaching sessions, for example, an e-learning course for gastroenterologists is already implemented.

Before developing the survey, we hypothesized three other instances in which gastroenterologists might deviate from the guideline: cases with adenomas with high-grade dysplasia, cases with tubulovillous adenomas, and cases where the guideline recommends returning to the national CRC screening program with fecal immunochemical test. Although cases involving HGD were answered according to the guideline by a majority of respondents, the gastroenterologists who did not answer in line with the guideline recommended an interval shorter than 1 year. In the US surveillance guideline and the guideline from the European Society of Gastrointestinal Endoscopy, HGD is considered a high-risk feature $[6,15]$. However, in the Dutch guideline, HGD is not incorporated as a separate risk factor, be- 
- Table 5 Short description of the 15 example cases with the recommended interval and rationale for deviating from the guideline.

\begin{tabular}{|c|c|c|c|c|c|c|c|c|c|c|c|c|c|}
\hline & \multicolumn{8}{|c|}{ Case Description } & \multicolumn{5}{|c|}{ Rationale for Deviation From Guideline } \\
\hline & \multicolumn{13}{|c|}{ Common cases } \\
\hline & Age & G & \# AD & $\begin{array}{l}\text { Size } \\
(\mathrm{mm})\end{array}$ & Vill. & HGD & \# prox & $\begin{array}{l}\text { Recommen- } \\
\text { ded interval }\end{array}$ & $\mathbf{N}$ & $\begin{array}{l}\% \text { ex- } \\
\text { pected } \\
\text { to be } \\
\text { correct }\end{array}$ & $\begin{array}{l}\text { \% based } \\
\text { on clini- } \\
\text { cal ex- } \\
\text { perience }\end{array}$ & $\begin{array}{l}\% \text { did } \\
\text { not } \\
\text { read } \\
\text { cor- } \\
\text { rectly }\end{array}$ & \% other \\
\hline 1 & 60 & M & 1 & 8 & $\mathrm{~T}$ & no & 0 & No surveillance & 6 & $0 \%$ & $17 \%$ & $83 \%$ & $0 \%$ \\
\hline 2 & 69 & M & 1 & 12 & $\mathrm{~T}$ & no & 0 & $5 y$ & 0 & & & & \\
\hline 3 & 54 & M & 1 & 20 & TV & no & 1 & $5 y$ & 21 & $62 \%$ & $10 \%$ & $10 \%$ & $19 \%^{1}$ \\
\hline 4 & 62 & $\mathrm{~F}$ & 2 & 22 & V & no & 0 & $3 y$ & 6 & $50 \%$ & $17 \%$ & $33 \%$ & $0 \%$ \\
\hline 5 & 63 & $\mathrm{~F}$ & 4 & 9 & V & no & 2 & $3 y$ & 4 & $50 \%$ & $0 \%$ & $50 \%$ & $0 \%$ \\
\hline 6 & 60 & $\mathrm{~F}$ & 5 & 12 & $\mathrm{~T}$ & no & 4 & $3 y$ & 1 & $0 \%$ & $0 \%$ & $100 \%$ & $0 \%$ \\
\hline 7 & 79 & M & 5 & 8 & $\mathrm{~T}$ & no & 3 & $\begin{array}{l}\text { Only if healthy, } \\
\text { then } 3 y\end{array}$ & 16 & $25 \%$ & $0 \%$ & $31 \%$ & $44 \%^{2}$ \\
\hline 8 & 75 & $M$ & 4 & 12 & $\mathrm{~T}$ & yes & 0 & $\begin{array}{l}\text { Only if healthy, } \\
\text { then } 5 y\end{array}$ & 25 & $32 \%$ & $0 \%$ & $44 \%$ & $24 \%^{2}$ \\
\hline \multirow[t]{3}{*}{9} & 65 & $M$ & 1 & 11 & TV & yes & 0 & $5 y$ & 6 & $50 \%$ & $0 \%$ & $17 \%$ & $33 \%^{3}$ \\
\hline & \multicolumn{13}{|c|}{ Serrated adenomas/polyps } \\
\hline & Age & G & \# SP & $\begin{array}{l}\text { Size } \\
(\mathbf{m m})\end{array}$ & & & \# prox & & $\mathbf{N}$ & & & & \\
\hline 10 & 58 & $\mathrm{~F}$ & 1 & 8 & & & 1 & No surveillance & 23 & $78 \%$ & $0 \%$ & $13 \%$ & $9 \%$ \\
\hline \multirow[t]{3}{*}{11} & 54 & $\mathrm{~F}$ & 2 & 12 & & & 2 & $5 y$ & 23 & $65 \%$ & $4 \%$ & $26 \%$ & $4 \%$ \\
\hline & \multicolumn{13}{|c|}{ Family history } \\
\hline & Age & G & Score & FM & $\begin{array}{l}\text { Age } \\
\text { FM }\end{array}$ & $\begin{array}{l}\text { Previ } \\
\text { exam }\end{array}$ & & & $\mathbf{N}$ & & & & \\
\hline 12 & 51 & M & 2 & Brother & $<50$ & $\begin{array}{l}\text { Yes, n } \\
\text { CRC }\end{array}$ & reditary & $5 y$ & 6 & $17 \%$ & $17 \%$ & $50 \%$ & $17 \%$ \\
\hline \multirow[t]{3}{*}{13} & 53 & M & 1 & Sister & $<50$ & no & & $\begin{array}{l}\text { Refer to ge- } \\
\text { neticist }\end{array}$ & 11 & $18 \%$ & $9 \%$ & $36 \%$ & $36 \%$ \\
\hline & \multicolumn{13}{|c|}{ Negative colonoscopies } \\
\hline & Age & G & $\begin{array}{l}\text { Initial } \\
\text { Score }\end{array}$ & \multicolumn{2}{|c|}{ \# neg. colo } & & & & $\mathbf{N}$ & & & & \\
\hline 14 & 69 & M & 4 & \multicolumn{2}{|l|}{1} & & & $5 y$ & 3 & $67 \%$ & $0 \%$ & $33 \%$ & $0 \%$ \\
\hline 15 & 63 & $\mathrm{~F}$ & 2 & \multicolumn{2}{|l|}{2} & & & No surveillance & 6 & $83 \%$ & $0 \%$ & $17 \%$ & $0 \%$ \\
\hline \multicolumn{9}{|c|}{ Total } & 157 & $48 \%$ & $4 \%$ & $30 \%$ & $17 \%$ \\
\hline
\end{tabular}

cause a meta-analysis and the study on which the guideline was based did not confirm HGD as an independent risk factor in addition to the other factors $[4,16]$. This is mainly explained by the fact that HGD is rarely seen in small $(<10 \mathrm{~mm})$ tubular or tubulovillous adenoma. Furthermore, there is significant interob- server variation between pathologists, making this feature an unreliable risk factor. In the interviews, half the gastroenterologists mentioned that they were not entirely convinced that HGD should not be incorporated, while one gastroenterologist in the interview specifically mentioned that HGD was not incor- 
porated in this score chart, but should be considered as highrisk, assigning a surveillance interval within 1 year.

Discrepancies for cases with a (tubulo)villous adenoma seemed to be caused by gastroenterologists scoring tubulovillous adenomas as villous adenomas. However, in previous studies, a tubulovillous adenoma ( $>25 \%$ and $<75 \%$ villous component) was not a risk factor for metachronous disease in a multivariable model $[4,17]$. Only villous adenoma (>75\% villous component) was found to be a risk factor [16], and therefore assigned an extra point to the risk score chart in the guideline. However, that might be confusing because internationally an advanced adenoma is defined as an adenoma $\geq 10 \mathrm{~mm}$, HGD, or a tubulovillous component (>25\%). Also, during the interviews, six of 10 gastroenterologists mentioned that adhering to the guideline was difficult considering the difference between tubulovillous and villous adenomas, because pathology reports in their hospital do not include percentages nor whether adenomas were villous or tubulovillous (Appendix 1).

In contrast to the cases discussed before, the case in which a person with only one distal non-advanced adenoma should return to the screening program was answered correctly by a large majority without striking discrepancies. Previously these patients would be recommended surveillance after 6 years, but apparently the change to recommend no surveillance is well accepted.

Adherence to our colonoscopy surveillance guideline is at the high end of adherence as reported in other studies. Median adherence to the guideline was reported to be $49 \%$ in France, $63 \%$ in Canada and $52.5 \%$ and $69 \%$ in the United States in two different periods. A study in the United States in primary care physicians found a far lower adherence of $29 \%$ [11-13, 1820]. More specifically, compared to the reported adherence in the Netherlands when the simple 2002 guideline was implemented, our estimate of adherence shows a clear increase with a median of $76 \%$ adherence, compared to [12] a median of $59 \%$ (range: $22 \%-80 \%$ ) in the survey based on the old guideline. This comparison clearly indicates that more complex guidelines do not necessarily lead to confusion and lower adherence, but that they might actually increase adherence. The reasons were not explored in our study, but possibly it is because they better align with physicians' clinical experience and international literature and guidelines.

An important strength of our study is that we based the survey on a pilot that consisted of interviews with 10 gastroenterologists, and that the pilot provided insight into which situations led to deviation from the guideline and the rationale for the deviation. However, our study also has three limitations. First, the response rate to the survey was low, which may have led to non-respondent bias. We did not see any differences in age and gender between respondents and the complete group and the number of correctly answered questions did not show a skewed distribution. Still, non-response bias could exist, given that the proportion of responding gastroenterologists was lower in academic hospitals (9.4\%) compared to other types of hospital (18.0\%). Previous studies have shown that adherence to guidelines is generally higher in academic hospitals, implying that we may have underestimated the adherence rate. On the other hand, some respondents asked for development of an elearning module of this survey, indicating that at least some of the responding endoscopists were eager to improve their knowledge about the guideline and were thus more likely to follow it. In that case, the estimated adherence rate could be overestimated.

Second, we only measured adherence to guidelines among gastroenterologists. This is not a limitation in the Netherlands, because there the vast majority of surveillance endoscopies are performed by gastroenterologists. However, it may hamper the generalizability of our findings to other settings where surveillance endoscopies may also be performed by surgeons or internists. If these clinicians have less knowledge about surveillance guidelines, adherence to guidelines may be lower in these settings.

Finally, our findings are based on a survey, while adherence in daily practice may be different for various reasons. It would be preferable to measure actual adherence rates. In a survey, gastroenterologists might give desirable answers although they deviate from guidelines in daily practice. Also, if a recommendation is given to a patient, the patient does not always show up after the correct interval.

Our study has four important practical implications. First, the fact that the most often quoted rationale for deviation from the guideline was misinterpretation for cases with serrated polyps clearly indicates that information about these polyps on the score chart or app needs to be improved. Second, it should be further highlighted that according to the guideline, HGD should not be taken into account when determining the interval. Moreover, gastroenterologists and pathologists need to discuss how to improve reporting of the villous or tubulovillous nature of an adenoma in the pathology report to facilitate classification of these lesions. At the time the national colorectal cancer screening program was introduced in 2014, protocols for structured endoscopy and pathology reports were also introduced with predefined categories for histology, which may improve classification of villous or tubulovillous adenoma. Finally, use of a pocket-sized score chart, app or other source when making surveillance interval recommendations should be encouraged as this improves adherence to the guideline.

It would be even better if, in the future, software could be integrated into the electronic patient dossier that would automatically determine the recommended surveillance interval based on registered polyp characteristics. That would improve interpretation of the guideline and noncompliance with it would require a manual override of the system.

The current Dutch guideline differs from other guidelines regarding level of risk stratification. While other guidelines divide patients into groups based on a simple heuristic using presence or absence of risk factors $[6,21,22]$ the Dutch guideline combines several risk factors into a score from 0 to 5 . The Dutch guideline is therefore more complex, which may cause misunderstandings and thereby decrease adherence. However, this study showed that more complexity in a guideline did not lower adherence as assessed in a survey, and that this guideline with risk stratification actually seemed to improve adherence. Because better risk-stratification leads to efficient use of sources 
and less unnecessary colonoscopies, this should encourage other countries to implement a guideline with more detailed risk-stratification.

\section{Conclusion}

In conclusion, median adherence to the updated colonoscopy surveillance guideline of $76 \%$ seems reasonable, and is higher than adherence to the previous guideline. This shows that detailed (more complex) risk stratification for designation of a surveillance interval is feasible. Adherence could potentially be improved by clarifying the correct interpretation of serrated polyps.

\section{Acknowledgements}

The autor thank the other members of the working group on the guideline for colonoscopy surveillance - A.M. van Berkel, Y. Hazewinkel, I. Nagtegaal, S. Sanduleanu and H. Vasen - for their critical review of the manuscript.

\section{Competing interests}

The authors declare that they have no conflict of interest.

\section{References}

[1] Jemal A, Bray F, Center MM et al. Global cancer statistics. CA Cancer ] Clin 2011; 61: 69-90

[2] Cottet V, Jooste V, Fournel I et al. Long-term risk of colorectal cancer after adenoma removal: a population-based cohort study. Gut 2012; 61: $1180-1186$

[3] Leung K, Pinsky P, Laiyemo AO et al. Ongoing colorectal cancer risk despite surveillance colonoscopy: the Polyp Prevention Trial Continued Follow-up Study. Gastrointest Endosc 2010; 71: 111-117

[4] Martinez ME, Baron JA, Lieberman DA et al. A pooled analysis of advanced colorectal neoplasia diagnoses after colonoscopic polypectomy. Gastroenterology 2009; 136: 832-841

[5] Atkin WS, Valori R, Kuipers EJ et al. European guidelines for quality assurance in colorectal cancer screening and diagnosis. First EditionColonoscopic surveillance following adenoma removal. Endoscopy 2012; 44: (Suppl. 03): 151-163

[6] Lieberman DA, Rex DK, Winawer S] et al. Guidelines for colonoscopy surveillance after screening and polypectomy: a consensus update by the US Multi-Society Task Force on Colorectal Cancer. Gastroenterology 2012; 143: 844-857
[7] Leddin D, Armstrong D, Borgaonkar M et al. The 2012 SAGE wait times program: Survey of Access to GastroEnterology in Canada. Can J Gastroenterol 2013; 27: 83-89

[8] Patel VB, Nahar R, Murray B et al. Exploring implications of Medicaid participation and wait times for colorectal screening on early detection efforts in Connecticut - a secret-shopper survey. Connecticut Med 2013; 77: 197-203

[9] Schreuders EH, Ruco A, Rabeneck L et al. Colorectal cancer screening: a global overview of existing programmes. Gut 2015; 64: 1637-1649

[10] Terhaar Sive Droste JS, Craanen ME, van der Hulst RW et al. Colonoscopic yield of colorectal neoplasia in daily clinical practice. World J Gastoenteroly 2009; 15: 1085-1092

[11] Huppertz ], Coriat R, Leblanc $S$ et al. Application of ANAES guidelines for colonoscopy in France: a practical survey. Gastroenterol Clin Bio$\log 2010$; 34: 541-548

[12] Mulder SA, Ouwendijk RJ, van Leerdam ME et al. A nationwide survey evaluating adherence to guidelines for follow-up after polypectomy or treatment for colorectal cancer. J Clin Gastroenterol 2008; 42: 487-492

[13] van Kooten $\mathrm{H}$, de Jonge V, Schreuders E et al. Awareness of postpolypectomy surveillance guidelines: a nationwide survey of colonoscopists in Canada. Can J Gastroenterol 2012; 26: 79-84

[14] NVMDL. CBO guideline. 2014: http://www.mdl.nl/uploads/240/1308/ Richtlijn_Coloscopie_Surveillance_definitief_2013.pdf

[15] Bonnington SN, Rutter MD. Surveillance of colonic polyps: Are we getting it right? World J Gastroenterol 2016; 22: 1925-1934

[16] van Heijningen EM, Lansdorp-Vogelaar I, Kuipers EJ et al. Features of adenoma and colonoscopy associated with recurrent colorectal neoplasia based on a large community-based study. Gastroenterology 2013; 144: 1410-1418

[17] de Jonge V, Sint Nicolaas J, van Leerdam ME et al. Systematic literature review and pooled analyses of risk factors for finding adenomas at surveillance colonoscopy. Endoscopy 2011; 43: 560-572

[18] Boolchand V, Olds G, Singh J et al. Colorectal screening after polypectomy: a national survey study of primary care physicians. Ann Internal Med 2006; 145: 654-659

[19] Iskandar H, Yan Y, Elwing J et al. Predictors of poor adherence of US gastroenterologists with colonoscopy screening and surveillance guidelines. Digest Dis Sci 2015; 60: 971-978

[20] Saini SD, Nayak RS, Kuhn L et al. Why don't gastroenterologists follow colon polyp surveillance guidelines? results of a national survey Journal of clinical gastroenterology 2009; 43: 554-558

[21] Hassan C, Quintero E, Dumonceau JM et al. Post-polypectomy colonoscopy surveillance: European Society of Gastrointestinal Endoscopy (ESGE) Guideline. Endoscopy 2013; 45: 842-851

[22] Matsuda T, Chiu HM, Sano Y et al. Surveillance colonoscopy after endoscopic treatment for colorectal neoplasia: From the standpoint of the Asia-Pacific region. Digest Endosc 2016; 28: 342-347 